\title{
Effects of Natura 2000 on nontarget bird and butterfly species based on citizen science data
}

\section{Pellissier, V.}

2020-06

Pellissier , V , Schmucki , R , Pe'er , G , Aunins , A , Brereton , T M , Brotons , L , Carnicer , J , Chodkiewicz , T , Chylarecki , P , del Moral , J C , Escandell , V , Evans , D , Foppen , R , Harpke , A , Heliölä , J , Herrando , S , Kuussaari , M , Kühn , E , Lehikoinen , A , Lindström , $\AA$ A, Moshøj, C M , Musche , M , Noble , D , Oliver , T H, Reif , J , Richard , D , Roy , D B , Schweiger, O , Settele , J , Stefanescu , C , Teufelbauer , N , Touroult, J , Trautmann , S , pÿvan Strien , A J , van Swaay , C A M , van Turnhout, C , Vermouzek, Z, VoYíaek , P , Jiguet , F \& Julliard , R 2020 , ' Effects of Natura 2000 on nontarget bird and butterfly species based on citizen science data ' , Conservation Biology , vol. 34 , no. 3 , pp. 666-676 . https://doi.org/10.1111/cobi.13434

http://hdl.handle.net/10138/321173

https://doi.org/10.1111/cobi.13434

acceptedVersion

Downloaded from Helda, University of Helsinki institutional repository.

This is an electronic reprint of the original article.

This reprint may differ from the original in pagination and typographic detail.

Please cite the original version. 
Effects of Natura 2000 on nontarget bird and butterfly species based on citizen science data

V. Pellissier ${ }^{1,2, *}$, R. Schmucki1, 3,4, G. Pe'er5, 6, 7, A. Aunins ${ }^{8,9}$, T.M. Brereton ${ }^{10}$, L. Brotons ${ }^{11,12,13}$, J. Carnicer11, 14, T. Chodkiewicz ${ }^{15,16}$, P. Chylarecki15, J.C. del Moral ${ }^{17}$, V. Escandell17, D. Evans ${ }^{18}$, R. Foppen $^{19}$, A. Harpke ${ }^{20}$, J. Heliölä21, S. Herrando ${ }^{12,13}$, M. Kuussaari²1, E. Kühn ${ }^{20}$, A. Lehikoinen ${ }^{22}$, Å. Lindström²3, C.M. Moshøj24, M. Musche²0, D. Noble25, T.H. Oliver²6, J. Reif27, 28, D. Richard ${ }^{18}$, D.B. Roy $^{29}$, O. Schweiger 20 , J. Settele ${ }^{5,20}$, C. Stefanescu11,30, N. Teufelbauer ${ }^{31}$, J. Touroult32, S. Trautmann ${ }^{33}$, A.J. van Strien ${ }^{34}$, C.A.M. van Swaay35, C. van Turnhout ${ }^{19,36}$, Z. Vermouzek ${ }^{37}$, P. Vořriššek $^{28,37}$, F. Jiguet ${ }^{1}$, R. Julliard ${ }^{1}$

\section{* Corresponding author:} vincent.pellissier@gmail.com

1. Sorbonne Université, MNHN-CNRS-UPMC, UMR7204-CESCO, 43 rue Buffon, CP 135, 75005 Paris, France.

2. Section for Ecoinformatics \& Biodiversity, Departement of Bioscience, Aarhus University, DK 8000, Aarhus, Denmark.

3. Centre de Synthèse et d'Analyse sur la Biodiversité, Immeuble Henri Poincaré, Domaine du Petit Arbois, Avenue Louis Philibert, 13857 Aix-en-Provence, France.

4. NERC Centre for Ecology \& Hydrology, Wallingford, Oxfordshire, OX10 8EF, UK.

This article has been accepted for publication and undergone full peer review but has not been through the copyediting, typesetting, pagination and proofreading process, which may lead to differences between this version and the Version of Record. Please cite this article as doi: 10.1111/cobi.13434.

This article is protected by copyright. All rights reserved. 
5. German Centre for Integrative Biodiversity Research (iDiv), Halle-Jena-Leipzig, Deutscher Platz 5e, 04103 Leipzig, Germany

6. UFZ - Helmholtz Centre for Environmental Research, Department Economics and Department Ecosystem Services, Permoserstr. 15, 04318 Leipzig, Germany

7. University of Leipzig

8. Faculty of Biology, University of Latvia, Jelgavas iela 1, Riga, LV-1004, Latvia

9. Latvian Ornithological Society, Skolas iela 3, Riga, LV-1010, Latvia

10. Butterfly Conservation, Manor Yard, East Lulworth, Wareham, Dorset, BH20 5QP, UK.

11. CSIC- CREAF, 08193 Cerdanyola del Vallès, Catalonia, Spain.

12. Catalan Ornithological Institute. Natural History Museum of Barcelona, Plaça Leonardo da Vinci 4-5, 08019 Barcelona, Catalonia, Spain

13. InForest JRU (CEMFOR-CTFC), 25280 Solsona, Catalonia, Spain

14. Department of Evolutionary Biology, Ecology and Environmental Sciences, University of Barcelona, 08028, Catalonia, Spain.

15. Museum \& Institute of Zoology, Polish Academy of Sciences, Wilcza 64, 00-679 Warszawa, Poland

16. Polish Society for the Protection of Birds (OTOP), ul. Odrowaza 24, 05-270 Marki, Poland 17. Sociedad Española de Ornitología (SEO/BirdLife), Melquíades Biencinto 34 ES-28053, Madrid, Spain

18. European Topic Centre on Biological Diversity, 57 rue Cuvier, 75005 Paris, France 19. Sovon Dutch Centre for Field Ornithology, PO Box 6521, 6503 GA Nijmegen, The Netherlands

This article is protected by copyright. All rights reserved. 
20. UFZ-Helmholtz Centre for Environmental Research, Department of Community Ecology, Theodor-Lieser-Strasse 4, 06120 Halle/Saale, Germany

21. Finnish Environment Institute (SYKE), Biodiversity Centre, P.O. Box 140, FI-00251 Helsinki, Finland

22. Finnish Museum of Natural History, P. O. Box 17, FI-00014 University of Helsinki, Finland.

23. Department of Biology, Biodiversity Unit, Lund University, Ecology Building, SE-223 62 Lund, Sweden

24. DOF-BirdLife Denmark, Vesterbrogade 140, DK-1620 Copenhagen V, Denmark

25. BTO, The Nunnery, Thetford, Norfolk IP24 2PU, UK

26. School of Biological Sciences, Harborne Building, Whiteknights campus, University of Reading, Berkshire, RG6 6AS, UK

27. Institute for Environmental Studies, Faculty of Science, Charles University, Prague, Czech Republic

28. Department of Zoology and Laboratory of Ornithology, Faculty of Science, Palacký University in Olomouc, 17. listopadu 50, 77143 Olomouc, Czech Republic

29. NERC Centre for Ecology \& Hydrology, Wallingford, Oxfordshire, OX10 8EF, UK 30. Museu de Ciències Naturals de Granollers, Francesc Macià 51, 08402 Granollers, Catalonia, Spain

31. BirdLife Austria, Museumplatz 1/10/8, A-1070 Wien, Austria

32. UMS 2006 PatriNat AFB, CNRS, MNHN; CP41, 36 rue Geoffroy Saint-Hilaire, 75005 Paris, France

33. DDA, An den Speichern 6, 48157 Münster, Germany

34. Statistics Netherlands, The Hague, The Netherlands

This article is protected by copyright. All rights reserved. 
35. Dutch Butterfly Conservation and Butterfly Conservation Europe, PO Box 506, NL 6700 AM Wageningen, The Netherlands

36. Department of Animal Ecology \& Ecophysiology, Institute for Water and Wetland Research, Radboud University, PO Box 9010, 6500 GL Nijmegen, The Netherlands

37. Czech Society for Ornithology, Na Bělidle 252/34, CZ-150 00 Prague 5, Czech Republic

Keywords: European protection network, species abundance, habitat specialization, Breeding Bird Survey, butterfly monitoring schemes, Birds and Habitats Directives

Running Head: Natura 2000

Article impact statement: Across Europe the abundance of a majority of nontarget birds and a quarter of nontarget butterflies increased with Natura 2000 coverage.

\section{ABSTRACT}

The European Union's Natura 2000 (N2000), is one of the largest international networks of protected areas. One of its aims is to secure the status of a pre-determined set of (targeted) bird and butterfly species. However, also non-target species may benefit from N2000. We evaluated how the terrestrial component of this network relates to the abundance of non-targeted, more common bird and butterfly species using data from long-term volunteer-based monitoring programs in 9,602 sites for birds and 2,001 sites for butterflies. In almost half of the 155 bird species assessed, and particularly among woodland specialists, abundance increased with the proportion of N2000 sites in the landscape. The corresponding positive relationship was found for 27 of the 104 butterfly species, although most of these species were generalists. These

This article is protected by copyright. All rights reserved. 
positive relationships disappeared for most of the species when land-cover covariates were taken into account, hinting that land-cover is a primary factor defining the positive effects of the N2000 network. The increase in abundance with N2000 was correlated with the specialization index for bird species, but not for butterfly species. Although the N2000 network supports higher abundance of a large spectrum of species, the low number of specialist butterfly species showing a positive association stresses the need to implement management plan improving the quality of habitats of N2000 areas potentially harboring openland butterfly specialists. For a better understanding of the processes involved, we advocate for a standardized collection of data on N2000 sites.

This article is protected by copyright. All rights reserved. 
INTRODUCTION

Large networks of protected areas are the cornerstone of conservation strategies to avert the loss of biodiversity. With its 27,700 designated sites distributed across the 28 European Union's (EU) member states, the Natura 2000 (N2000) network is one of the world's largest coordinated efforts to preserve biodiversity at a continental scale (Figure S1). The network, a key part of the EU's conservation strategy, is formed by sites designated under the EU Birds Directive or the EU Habitats Directive and covers 18\% of the EU's land area (Kati et al. 2014). N2000 is directly targeted at conserving an extensive range of habitats and species considered interesting due to their rarity, vulnerability or characteristics typical of their region. While the phase during which member States designate areas to protect is now nearly complete, management plans still have to be implemented for slightly less than half of the sites (Kati et al. 2014; Milieu et al. 2016).

While conservation efforts like N2000 target a selected set of endangered species, more common (non-targeted) species play a crucial role in ecosystem structure and functioning (Gaston 2010) and their declines could have important evolutionary and ecological consequences by disrupting food webs and altering macro-ecological patterns (Gaston 2011). Recent studies (Lisón et al. 2013, 2015; Maiorano et al. 2015; Kukkala et al. 2016) showed that the N2000 network overlaps with an important part of many vertebrate species distribution, including species are not specifically targeted by the directives, highlighting a potential for N2000 designated biodiversity features - species or habitats - to act as surrogates for a wide range of species (Margules \& Pressey 2000).

Studies conducted at the national level in France showed that the abundances of the majority of non-target bird (Pellissier et al. 2013) and bat species (Kerbiriou et al. 2018) tended to be

This article is protected by copyright. All rights reserved. 
higher in N2000 areas than in the wider countryside, and that animal communities are more specialized, with longer trophic chains in such areas .Even though Van Der Sluis et al. (2016) showed that a greater proportion of targeted and non-targeted plants, birds, butterflies, mammals, reptiles and amphibians species occurred inside N2000 than outside, little is known about the relative abundance of non-target species inside $v s$. outside N2000 as this study mainly focused on species richness

In this paper we assess the state of biodiversity, as reflected by the abundance of non-target species, within and around the designated areas of the network. This study focuses on two taxonomic groups, birds and butterflies as these taxa comprised, a large number of endangered or declining species and are well surveyed with the aim of assessing whether the designation of N2000 areas are also beneficial for non-target species.The hypothesis behind that aim is that species and habitats targeted by N2000 act as surrogates for biodiversity at large, and hence incidentally represent other species, i.e. capture known or unknown features of conservation interest by protecting focal features (Bridge et al. 2016) and define management requirements (either under the Birds and Habitats' Directives or under the Common Agricultural Policy) that benefit a larger range of species. While birds and butterflies are not necessarily the best surrogate species for other taxa (Billeter et al. 2008), here we only considered the target species as surrogates from the non-target species. As most of the N2000 sites are not regularly surveyed for their biodiversity, our analyses are not restricted within the specific borders of the N2000 sites, but cover monitoring sites within and around the network, asking whether landscapes i.e. the $1 \mathrm{~km}$-radius area around monitoring sites - with larger areas under the N2000 designation show better ecological status from the bird and butterfly perspective. We also

This article is protected by copyright. All rights reserved. 
investigated whether species-specific ecological characteristics could explain which species were positively correlated to the amount of N2000 areas.

Using abundance data from systematic long-term monitoring schemes, we first evaluated the relationship between the N2000 coverage in the landscape and the abundance of different species. Second, we evaluated to what extent the variability in abundance could be explained by species characteristics. Finally, as Europe encompasses a large variety of climate and geographical features, we examined the variation across Europe's biogeographical regions (EEA 2016).

\section{METHODS}

\section{Bird and butterfly survey}

We selected bird and butterfly species using all the following criteria: (i) species not listed in the Annex 1 of the Bird directive or in the Annex 2 of the Habitat directive, because the main focus of the article are non-target species, (ii) species with their distribution range (Kudrna et al. 2011; BirdLife International \& NatureServe 2013) overlapping with at least 30 monitoring sites, in order to have enough data points to model species abundance, and (iii) species occurring at least in $10 \%$ of the monitoring sites located inside their distribution range, to avoid an excessive number of zeros.

Bird data were provided for 155 species by 14 Bird Breeding Surveys (BBS) established in Austria, Catalonia, Czech Republic, Denmark, Finland, France, Germany, Italy, Latvia, Netherlands, Poland, Spain, Sweden and the United Kingdom (Figure 1). These monitoring

This article is protected by copyright. All rights reserved. 
schemes covered 9,602 sites from 2001 to 2011, a monitoring site being defined as a location in which the abundance was monitored in at least two different years. Depending on the scheme, three types of field survey were used: point count, line transect or territory mapping (see PECBMS 2018 for more details on the bird data). In each monitoring site, we used the aggregated count, i.e. the abundances summed across points or transect, or the total abundance mapped.

Butterfly data were gathered from six Butterfly Monitoring Schemes (BMS) established in Catalonia, France, Finland, Germany, The Netherlands and UK. From the BMSs, we extracted butterfly counts for 104 species collected across 3,439 monitoring sites from 2001 to 2012, restricted to 2006-2012 in Germany and France. From weekly butterfly counts, we derived local abundance indices, using the regional GAM method, an extension of the two-stage modelling approach described by Dennis et al. (2013), accounting for variation in species phenology across years and climatic regions (see details in Schmucki et al. 2016). We further restricted our analysis to monitoring sites where at least $70 \%$ of the active flight period was covered (Schmucki et al. 2016). This led to the removal of all monitoring sites from the French BMS and reduced the butterfly dataset to 2,001 BMS sites (Figure 1).

Bird and butterfly species were classified according to their habitat preferences. For birds, the preferences were retrieved in the list defined by the European Bird Census Council (PECBMS 2007). For butterflies, we used the division of butterflies into grassland and woodland specialists from Van Swaay et al. (2006).

Spatial data

This article is protected by copyright. All rights reserved. 
N2000 boundaries were taken from the 2012 spatial database provided by the European Environmental Agency (EEA 2012a). We measured the area covered by N2000 in a buffer around the centroid of each monitoring site. The radius of the buffer was set to $1000 \mathrm{~m}$ (Pellissier et al. 2013) but we conducted sensitivity analyses using 500m and $200 \mathrm{~m}$ buffers. We assessed the land-cover around monitoring sites, using the CORINE Land-Cover 2006 database version 16 (EEA 2012b). The 44 land-cover classes were reclassified into six broader categories: farmland (arable land only), grassland, woodland, urban areas, wetland and water bodies. In order to reduce the collinearity between land-cover variables, we performed a PCA using the six above mentioned categories. We kept the first 4 principal components which explained $82 \%$ of the land-cover variability for the bird dataset and $82 \%$ of the land-cover variability for the butterfly dataset (see Figure S2 and S3 for details).

\section{Statistical analyses}

To test the effect of the coverage of N2000 on the abundance of each of the 155 bird and 104 butterfly species, we estimated the relationship between the abundance of each species and the coverage of N2000 around the monitoring sites. We used one generalized linear mixed effects models (GLMM) per species with the species abundance averaged across years (in order to avoid pseudo-replication issues due to a repeated sampling) as the dependent variable using the following modelling approach:

$\mathrm{Y} \% \mathrm{~N} 2000+\operatorname{offset}(\log ($ effort $))+(1 \mid$ scheme $)$ eq. 2

This article is protected by copyright. All rights reserved. 
$\mathrm{Y} \sim \% \mathrm{~N} 2000+\mathrm{PC} 1+\mathrm{PC} 2+\mathrm{PC} 3+\mathrm{PC} 4+$ offset(log(effort $))+(1 \mid$ scheme $) \quad$ eq. 3

With Y the abundance of the species, PC1 to PC4 are descriptors of the land-cover, $\%$ N2000 the proportion of N2000 around monitoring site, and effort a measure of the sampling effort added as an offset. This metric allows accounting for the variability in the duration and the surface of the surveys (see Appendix 3 for a detailed explanation). We added the scheme name as a random effect in order to account for remaining variation due to different sampling schemes. The first model (eq. 2) allowed us to determine whether the abundance of a given species is determined by the amount of N2000 in the landscape. The second model (eq. 3), by adding landcover descriptors as covariates allowed us to determine whether land-cover could account for the role of N2000 coverage as an explanatory variable. As the coverage of N2000 is not correlated with longitude ( $r=0.08$ for the BBS dataset and $r=0.04$ for the BMS dataset) and exhibit a low correlation with latitude $(r=-0.19$ for the BBS dataset and $r=-0.24$ for the BMS dataset) we did not account for latitudinal and longitudinal effects.

Abundance data often have zero-inflated distribution, making it crucial to use models with suitable distributions to tackle this issue. Here, averaging abundance data across years generates continuous data rendered the use of zero-inflated Poisson distribution impossible. The models were fitted using a Tweedie compound Poisson distribution and a log-link. The Tweedie compound Poisson distribution is a mixture of a degenerate distribution at the origin and a continuous distribution superior to zero and is used in situations where continuous data with exact zero occurs. It has been shown to outperform other zero-inflated models (Lecomte et

This article is protected by copyright. All rights reserved. 
al. 2013) and offers the advantage of providing a single estimate, while zero-inflated models model presence and abundance separately.

To examine the potential differences in the effect of N2000 on bird and butterfly abundance across regions, we performed a second set of analyses focusing on four distinct biogeographic regions, i.e. the Atlantic, Boreal, Continental and Mediterranean, (EEA 2016, Figure S1) and using subsets of monitoring sites and species $(120,108,118$ and 104 bird species and 33, 28, 55 and 72 butterfly species, respectively. The Alpine, Black Sea, Steppic and Pannonian regions were excluded from the two sets of analyses because of the low number of sites monitored.

\section{Ecological characteristics of species}

To assess whether the ecological characteristics of the species influence the relationship between their abundance and N2000, we tested how the relationship between abundance and N2000 coverage was related to their level of habitat specialization measured by the Species Specialization Index (SSI; Julliard et al. 2006). Species with higher SSI are characterized by narrower niche and restricted to fewer habitats and are therefore considered to be habitat specialists. For birds we used the SSI measured by Le Viol et al. (2012) for European species and defined as the coefficient of variation of the abundance across habitats. The SSI for butterflies was based on the biotope profiles which were calculated for each European species in Van Swaay et al. (2006). A group of national butterfly experts classified the main biotopes for each species in their country using level 1 CORINE biotope classes (Moss et al. 1991). Then, for each species, the number of times each biotope was mentioned was computed as a percentage and the SSI zqs computed as the variance of these percentages. We modelled slope of the

This article is protected by copyright. All rights reserved. 
relationship between abundance and N2000 coverage (eq. 2) as a function of their SSI values with a generalized additive model (GAM). We used a GAM to account for potential non-linear relationships. To account for variation in the precision of the slope of the relationship of species abundance with N2000 coverage for each species, we weighted each estimate with the inverse of its standard deviation.

All statistical analyses were computed using R 3.4.0 (R Core Team, 2017) with the cplm (Zhang 2013) and mgcv packages (Wood 2011) .

\section{RESULTS}

\section{Bird and butterfly abundance}

The results were qualitatively similar for the different radii used to assess the N2000 coverage around each site so only the results for the $1000 \mathrm{~m}$ radius are presented (Figure S4-S7).

The abundances of $47 \%$ of the 155 bird species ( $n=73$ species) were positively associated $(P<$ 0.05) with the coverage of N2000 around the monitoring site (Figure 2, Table S5), of which 24 are woodland (such as Dryobates minor or Anthus trivialis) and 5 are farmland species. 40 bird species showed a negative association with the N2000 coverage. Out of the 104 butterfly species, $25 \%$ ( $n=27$ species) showed a positive relationship with N2000 coverage, of which 2 are distinctive grassland species (Melitaea trivia and Cyaniris semiargus) and 2 are woodland species. (Figure 2, Table S6). 16 butterfly species showed a significant negative association with the N2000 coverage.

This article is protected by copyright. All rights reserved. 
After accounting for the land-cover, fewer species showed a relationship between abundance and N2000 coverage but the overall pattern remained largely identical to the analyses not accounting for land-cover, with more bird species than butterfly species exhibiting a positive relationship (resp. 32\% and 11\%, Figure 2, Table S7-S8).

The Atlantic and Continental patterns were similar (Table S9; Figure S8 and Figure S10) with $46 \%$ and $39 \%$ of bird species having a positive relationship between abundance and N2000, and $21 \%$ and $13 \%$ of butterfly species exhibiting a positive relationship. Again, the number of species with a positive relationship dropped after including land-cover covariates (Table S11). In the Boreal region, a very low number of bird and butterfly species exhibited a positive relationship between abundance and $\mathrm{N} 2000$ (respectively $5 \%$ and $7 \%$, shifting to $6 \%$ and $4 \%$ after including covariates, Figure S9). The Mediterranean region had a similar pattern for birds and butterflies, with $18 \%$ and $19 \%$ of bird and butterfly species exhibiting a positive relationship between their abundance and N2000, dropping to $11 \%$ and $4 \%$ after including land-cover covariates (Figure S11).

\section{Abundance variations and specialization}

Bird species characterized by higher level of habitat specialization also had a stronger positive relationship with $\mathrm{N} 2000$ coverage (Figure $\left.3 ; \mathrm{F}_{1,146}=11.8 \mathrm{P}=0.001\right)$ but not butterflies $\left(\mathrm{F}_{1.9,104}=\right.$ $2.7, \mathrm{P}=0.08)$. In the Atlantic region, abundance was highest in N2000 sites for species with intermediate levels of habitat specialization (Figure S12, $\mathrm{F}_{3.2,116}=3.9, \mathrm{P}<0.01$ ). The relationship was not significant for butterflies (Figure $\mathrm{S} 12, \mathrm{~F}_{1.7,33}=0.8, \mathrm{P}=0.56$ ). In the Continental region, the bird and butterfly species characterized by higher level of habitat specialization also had a

This article is protected by copyright. All rights reserved. 
stronger positive relationship with $\mathrm{N} 2000$ coverage (Figure S14; Birds: $\mathrm{F}_{1,114}=3.9, \mathrm{P}=0.05$;

Butterflies: $\left.F_{1,55}=13.2, P=0.001\right)$. Finally, no relationships were found in the Boreal and Mediterranean regions, except for birds in the Boreal region (Boreal: Birds: $\mathrm{F}_{1,98}=5.5, \mathrm{P}=0.02$; Butterflies: $F_{1,29}=0.77, P=0.39$; Figure S13. Mediterranean: Birds: $F_{1,123}=2.9, P=0.09$ Butterflies: $F_{1,72}=0.30, P=0.59$; Figure S15).

\section{DISCUSSION}

\section{Abundance variations with N2000 coverage}

N2000 sites, designated because of the presence of targeted species and habitats, also harbor a substantial number of non-target bird and butterfly. We found that the abundance of half of the non-target bird species observed increased with the coverage of N2000 in the surrounding landscape. The abundance of only a quarter of the butterfly species had a positive association with the coverage of N2000 in the landscape. Van Der Sluis et al. (2016) already showed the incidental effect of N2000 on the species richness of non-target species, with more non-target species inside N2000 than outside. Here, we go further and show that N2000 can also benefit non-Annex species populations by providing a similar incidental effect i.e. capturing features of conservation interest by protecting focal features. While such a designation effect has been shown at the national level by Pellissier et al. (2013) and Kerbiriou et al. (2018) for birds and bats, it is to our knowledge the first time that it is shown at a pan-European scale. The designation of areas as areas of ecological or natural interest can drive changes beneficial to biodiversity even in the absence of legal protection tools. For exemple, Mimet et al. (2013) showed that the designation process can influence the urbanization rate of an area. Similarly,

This article is protected by copyright. All rights reserved. 
designation for protection may halt road expansion and with it a cascade of factors leading to habitat degradation (Ibisch et al. 2016).

Habitat specialization and Natura 2000.

The bird species with higher relative abundance on N2000 areas are more likely to be habitat specialists, with the specialization index increasing with the slope of the relationship between abundance and N2000 coverage around the monitoring sites. When considering the whole network across the EU, woodland bird species often exhibit the strongest relationship with N2000 coverage - for instance the Lesser spotted woodpecker (Dryobates minor) or the Tree pipit (Anthus trivialis). Increase in abundance for woodland specialists, combined with the increase in specialization with the slope of the relationship between abundance and N2000 coverage as well as the bias in N2000 toward woodland sites thus hint that the N2000 network has the potential to be an efficient tool to help mitigating the overall decline of bird woodland specialists (Devictor et al. 2010; Le Viol et al. 2012).

In contrast, only a few farmland specialists had higher abundances when the proportion of N2000 area increased in the surrounding landscape. It should however be noted that this does not pertain to the capacity of N2000 to reverse the decline of farmland species in Europe. Even though habitat preferences may exhibit regional variations, a closer look at the ecology of species reveals that the species having a positive association with the N2000 coverage are far from being dependent on typical farmland (mosaic of cropland and grassland or extensive grassland). For example, the Meadow pipit (Anthus pratensis) can be found in grass moor or extensive grassland, while the Cattle egret (Bubulcus ibis) or the Whinchat (Saxicola rubetra) are

This article is protected by copyright. All rights reserved. 
closely associated with wetland or wet pastures. The Northern lapwing (Vanellus vanellus) can be found in wet pastures or mosaic of cropland and grassland (BirdLife International 2018). As N2000 farmland habitat exhibit features close to High Nature Value Farmland (high proportion of semi-natural vegetation, low intensity mosaic farming ; Paracchini et al. 2008), these particular species are thus far more likely to be selected in the farmland located inside N2000 than species typical of arable land (Rock sparrow - Petronia petronia- and Common linnet -

\section{Carduelis cannabina).}

The abundance of only two butterfly grassland specialists - the Lesser spotted fritillary (Melitaea trivia) and the Mazarine blue (Cyaniris semiargus) - increased with N2000 coverage. These results for grassland butterflies offer a spatial dimension concurring with other temporaloriented studies, both on the national and EU level. Studies indicate a severe decline of grassland butterflies throughout Europe (Van Swaay et al. 2007; Thomas 2016), of insect biomass in protected areas in Germany (Hallmann et al. 2017), and recent and ongoing decline in butterflies in Germany not limited by N2000 (Rada et al. 2019). Even though the negative bias toward grassland in N2000 sites (Figure S16) may partly drive the under-representation of grassland butterflies in N2000, these grassland are also poorly conserved (EEA 2015). This under-representation of grassland butterflies thus likely relates to insufficient implementation of good-practice standards for grassland management, both within and outside N2000 areas (see e.g. Konvicka et al. 2008). In this context it should be noted that grassland management in the EU and hence in N2000 is largely determined by the Common Agricultural Policy (CAP). Insufficient budget allocation to N2000 and Agri-Environment-Climate Schemes (Pe'er et al. 2017) under the CAP may prevent the implementation of appropriate management practices.

This article is protected by copyright. All rights reserved. 
Forest butterflies did not show high abundances even when N2000 coverage is high. One possible explanation is that even the butterfly species most associated with forest are not specialists of deep, closed forest, which are found in proportionally greater frequency within the N2000 network (Figure S16) but more with clearing and edges. Kadlec et al. (2018) showed that trait richness decreased in native European forests, following a closure in canopy due to forestry activities, hinting that close forests might harbour less specialized butterfly species. In addition, the lack of good management practices at the European scale is leading to an increase in forest closure, especially in protected areas (Maes et al. 2013b).

Finally, the surrogate approach used here - how can the protection of a taxa protect other taxa has been shown to be sensible to differences in ecological requirements between the surrogate and the target taxa, but also to the diversity of the surrogate taxa (Bladt et al. 2008). Even though N2000 has shown efficiency in protecting some butterfly species (Verovnik et al. 2011) the effect of N2000 on the abundance of non-target butterfly species might be lower than expected due to the low number of N2000 sites covering the typical habitat requirements of butterflies. For non-target butterflies at least, this implies that the ability Habitat and Birds directives ability to represent other conservation features in a surrogacy framework is limited. It been argued that some improvement might be achieved by re-visiting the rules for site selection to give more attention to the taxa with specific habitat requirements such as butterflies or by altering the target species list (Hochkirch et al. 2013). Modifying the Annexes could however divert the attention and resources that could otherwise be invested toward better sites management. As a lot of threatened butterfly species are absent from the Annexes using Red-Lists to identify management priorities and funding the implementation of necessary

This article is protected by copyright. All rights reserved. 
management measures should be a priority before revising the designation criteria for N2000 sites (Maes et al. 2013a).

\section{Geographic variations}

The abundance patterns for birds are identical in the Atlantic and Continental regions and fairly similar to the overall pattern, while the abundance patterns are markedly divergent from the Pan-European pattern in the Boreal and Mediterranean region. Moreover, only in the Atlantic and Continental region, and to a lesser extent in the Mediterranean region, are woodland bird specialists more abundant in N2000. This discrepancy between the biogeographic regions might be caused by differences in landscape composition across the various regions. Indeed, in the Continental region (as in the whole of Europe), the coverage of forest increases with the coverage of N2000. This accrued abundance of woodland species is less clear in the Mediterranean region, where the forest coverage is the lowest. In contrast, in the Boreal region where the pattern was not detected either, the forest coverage is very high (Figure S16). Thus, this lack of variation in forest coverage might explain the lack of positive association between forest specialists and N2000. Furthermore, the N2000 coverage in the Boreal region is much higher in the species-poor northern areas than in the species-rich southern areas (Figure S17). This could reduce the importance of the N2000 sites for many non-target species in general since systematically selected census sites are more likely to be situated next to the N2000 area in the north which holds in general fewer non-target species than southern ones. This highlights the unequal coverage of $\mathrm{N} 2000$ sites within different biogeographic regions and the importance

This article is protected by copyright. All rights reserved. 
of strengthening the protected area network in the southern part of the Boreal region (Virkkala \& Rajasärkkä 2007).

\section{Limitations}

It is important to keep in mind that the sampling design is far from complete for the butterfly monitoring scheme.Boreal and Mediterranean regions are underrepresented in our data set, which might hamper our ability to draw firm conclusions for these regions. Further, in the Boreal region the number of monitoring sites including a part of a N2000 area is quite limited (Figure S17). Though we found a relationship between SSI and the response of species abundance to $\mathrm{N} 2000$, one should keep in mind that the relation is mostly driven by a small number of species having a high SSI. The bird's and butterfly's SSI were computed using expert based assessment of the frequency of land-cover (Le Viol et al. 2012), introducing some subjectivity in the computation of the SSI. Computing these indices using actual habitat data from the monitoring sites might allow us to gain a deeper insight in the relationship of bird and butterfly species abundance in relation to N2000 in the future. While we accounted for the variation in sampling effort, the nature of our data did not allow us to account for the variation in detection probability in our model. Even though this could lead to systematic errors, we are only interested in the variation of single species abundance and not in the comparison of the abundance between species, making us confident confident in the broad patterns demonstrated in our results (Pellissier et al. 2013).

This article is protected by copyright. All rights reserved. 


\section{Conclusions}

Here we show for the first time at the European scale that the N2000 network can incidentally represent non-focal biodiversity. Non-focal bird species - and butterfly to a lesser extent - were also being captured in landscapes with high N2000 coverage and incidentally represented. As the incidental protection was rather low for butterfly species, future research should focus on accounting for the different response of butterflies to N2000. Our analysis only encompassed specialisation and abundance as metrics of biodiversity, but future research should focus on various metrics - mortality, age structure, reproductive rate... - to be able to see the bigger picture. As a matter of fact, our results do not yet integrate the effects of the management of N2000 sites. Even though N2000 often overlap with areas protected by previous national or regional laws (Evans 2012), meaning that active management is already in place in countries where all nature reserves or national parks were turned into N2000 areas (Sweden, Estonia), there are still many sites which are not managed (Milieu et al. 2016). In order to pursue the evaluation of the efficiency of the N2000 network and get a bigger picture, it is important to integrate a temporal aspect and management information into future analyses. Temporal analyses will allow us measuring the effect of any management on biodiversity while accounting for any lag between the management and actual effect on biodiversity (Donald et al. 2007). To this end, expansion of monitoring efforts, and its support by policy, is essential. Insofar, the monitoring network is based primarily on volunteer work and poorly supported by European policies, while butterflies are not even acknowledged as an official indicator despite wellfounded literature to support their use as such (e.g. van Swaay et al, 2007). Furthermore, as information on the management of N2000 site are not readily available in a single dataset, we advocate here for the establishment of a standardized collection of information about the

This article is protected by copyright. All rights reserved. 
management of N2000 sites, in order to increase our knowledge on the efficiency of Europe's protected are network.

\section{ACKNOWLEDGMENTS}

The authors wish to gratefully thank all the volunteers for their field work. Without their help, continent wide indicators and analyses are not possible. The authors also thank Elisabetta de Carli for providing data from the Italian breeding bird survey and Henning Heldbjerg for providing the bird survey data from Denmark. This work was done as part of the work programme of European Topic Centre on Biological Diversity action, funded by the European Environment Agency. VP also acknowledges the financial support of the Aarhus University Research Foundation under the AU Ideas program, through the Center for Informatics Research on Complexity in Ecology (CIRCE). RS was funded by the Fondation pour la Recherche sur la Biodiversité and Electricité de France S.A. (Centre for the Synthesis and Analysis of Biodiversity, project LOLA-BMS). AL was funded by the Academy of Finland (grant 275606). The Ministry of Environment has supported line transect censuses in Finland. The bird surveys in Sweden were supported by grants from the Swedish Environmental Protection Agency, and carried out in collaboration with all 21 County Administrative Boards of Sweden. The bird surveys are carried out within the framework of the Centre for Animal Movement Research and the strategic research environment Biodiversity and Ecosystem Services in a Changing Climate (BECC). LB was funded by MINECO through the project INMODES (CGL2017-89999-C2). JR was funded by the Czech Science Foundation (Grant 18-16738S).

This article is protected by copyright. All rights reserved. 


\section{SUPPORTING INFORMATION}

Appendix 1. The Natura 2000 network

Appendix 2. Results of the PCA carried out on land-cover data

Appendix 3. Bird and butterfly species sampling efforts

Appendix 4. Sensitivity analyses of the radius size

Appendix 5. Species specific relationships between abundance and the N2000 coverage

Appendix 6. Results per biogeographic regions.

Appendix 7. Description of the land-cover and N2000 coverage around monitoring sites.

Butterfly data can be requested through national scheme coordinators (http://www.butterfly-

monitoring.net/ebms), for data access policy of bird data see https://pecbms.info/use-of-theresults/data-access-policy/.

\section{REFERENCES}

Billeter R et al. 2008. Indicators for biodiversity in agricultural landscapes: A pan-European study. Journal of Applied Ecology 45:141-150.

BirdLife International. 2018. IUCN Red List for bird species. Available from www.birdlife.org (accessed July 20, 2018).

This article is protected by copyright. All rights reserved. 
BirdLife International, NatureServe. 2013. Bird species distribution maps of the world. Version 3.0. BirdLife International, Cambridge, UK and NatureServe, Arlington, USA.

Bladt J, Larsen FW, Rahbek C. 2008. Does taxonomic diversity in indicator groups influence their effectiveness in identifying priority areas for species conservation? Animal Conservation 11:546-554.

Bridge TCL, Grech AM, Pressey RL. 2016. Factors influencing incidental representation of previously unknown conservation features in marine protected areas. Conservation Biology 30:154-165.

Dennis EB, Freeman SN, Brereton T, Roy DB. 2013. Indexing butterfly abundance whilst accounting for missing counts and variability in seasonal pattern. Methods in Ecology and Evolution 4:637-645.

Devictor V, Clavel J, Julliard R, Lavergne S, Mouillot D, Thuiller W, Venail P, Villéger S, Mouquet N. 2010. Defining and measuring ecological specialization. Journal of Applied Ecology 47:15-25.

Donald PF, Sanderson FJ, Burfield IJ, Bierman SM, Gregory RD, Waliczky Z. 2007. International conservation policy delivers benefits for birds in Europe. Science 317:810-3.

EEA. 2012a. Natura 2000 data - the European network of protected sites. Available from https://www.eea.europa.eu/data-and-maps/data/natura-2 (accessed January 1, 2014).

EEA. 2012b. Corine Land Cover 2006 raster data. Available from https://www.eea.europa.eu/data-and-maps/data/corine-land-cover-2006-raster-2 (accessed January 1, 2014).

This article is protected by copyright. All rights reserved. 
EEA. 2015. The State of Nature in the European Union - Results from reporting under the nature directives 2007-2012.

EEA. 2016. Biogeographical regions. Available from https://www.eea.europa.eu/data-andmaps/data/biogeographical-regions-europe-3 (accessed July 16, 2018).

Evans D. 2012. Building the European Union's Natura 2000 network. Nature Conservation 1:1126.

Gaston KJ. 2010. Valuing common species. Science 327:154-155.

Gaston KJ. 2011. Common Ecology. BioScience 61:354-362.

Hallmann CA et al. 2017. More than 75 percent decline over 27 years in total flying insect biomass in protected areas. Plos One 12:e0185809.

Hochkirch A et al. 2013. Europe Needs a New Vision for a Natura 2020 Network. Conservation Letters 6:462-467.

Ibisch PL, Hoffmann MT, Kreft S, Pe’Er G, Kati V, Biber-Freudenberger L, DellaSala DA, Vale MM, Hobson PR, Selva N. 2016. A global map of roadless areas and their conservation status. Science 354:1423-1427.

Julliard R, Clavel J, Devictor V, Jiguet F, Couvet D. 2006. Spatial segregation of specialists and generalists in bird communities. Ecology letters 9:1237-44.

Kadlec T, Štrobl M, Hanzelka J, Hejda M, Reif J. 2018. Changes in community composition of nocturnal Lepidoptera caused by different habitat structure of native and invaded forests. Biodiversity and Conservation 27:2661-2680.

This article is protected by copyright. All rights reserved. 
Kati V, Hovardas T, Dieterich M, Ibisch PL, Mihok B, Selva N. 2014. The challenge of implementing the European network of protected areas natura 2000. Conservation Biology 29:260-270.

Konvicka M, Benes J, Cizek O, Kopecek F, Konvicka O, Vitaz L. 2008. How too much care kills species: Grassland reserves, agri-environmental schemes and extinction of Colias myrmidone (Lepidoptera: Pieridae) from its former stronghold. Journal of Insect Conservation 12:519-525.

Kudrna O, Harpke A, Lux K, Pennerstorfer J, Schweiger O, Settele J, Wiemers M. 2011. Distribution Atlas of Butterflies in Europe. Halle, Germany.

Kukkala AS, Santangeli A, Butchart SHM, Maiorano L, Ramirez I, Burfield IJ, Moilanen A. 2016. Coverage of vertebrate species distributions by Important Bird and Biodiversity Areas and Special Protection Areas in the European Union. Biological Conservation 202:1-9.

Le Viol I, Jiguet F, Brotons L, Herrando S, Lindström A, Pearce-Higgins JW, Reif J, Van Turnhout C, Devictor V. 2012. More and more generalists: two decades of changes in the European avifauna. Biology Letters 8:780-782.

Lecomte JB, Benoît HP, Ancelet S, Etienne MP, Bel L, Parent E. 2013. Compound Poisson-gamma vs. delta-gamma to handle zero-inflated continuous data under a variable sampling volume. Methods in Ecology and Evolution 4:1159-1166.

Lisón F, Palazón JA, Calvo JF. 2013. Effectiveness of the Natura 2000 Network for the conservation of cave-dwelling bats in a Mediterranean region. Animal Conservation 16.

Lisón F, Sánchez-Fernández D, Calvo JF. 2015. Are species listed in the Annex II of the Habitats This article is protected by copyright. All rights reserved. 
Directive better represented in Natura 2000 network than the remaining species? A test using Spanish bats. Biodiversity and Conservation 24:2459-2473.

Maes D, Collins S, Munguira ML, Šašić M, Settele J, van Swaay C, Verovnik R, Warren M, Wiemers M, Wynhoff I. 2013a. Not the Right Time to Amend the Annexes of the European Habitats Directive. Conservation Letters 6:468-469.

Maes J et al. 2013b. Mapping and Assessment of Ecosystems and their Services. An analytical framework for ecosystem assessments under action 5 of the EU biodiversity strategy to 2020. European Commission.

Maiorano L, Amori G, Montemaggiori A, Rondinini C, Santini L, Saura S, Boitani L. 2015. On how much biodiversity is covered in Europe by national protected areas and by the Natura 2000 network: Insights from terrestrial vertebrates. Conservation Biology 29:986-995.

Margules CR, Pressey RL. 2000. Systematic conservation planning. Nature 405:243-53.

Milieu, IEEP, ICF. 2016. Evaluation Study to support the Fitness Check of the Birds and Habitats Directives. European Commission.

Mimet A, Raymond R, Simon L, Julliard R. 2013. Can designation without regulation preserve land in the face of urbanization? A case study of ZNIEFFs in the Paris region. Applied Geography 45:342-352.

Moss D, Wyatt B, Cornaert MH, Roekaerts M. 1991. CORINE biotopes: The design, compilation and use of an inventory of sites of major importance for nature conservation in the European Community. Commission of the European Communities.

This article is protected by copyright. All rights reserved. 
Natura 2000 role for non-target species

Paracchini ML, Petersen J-E, Hoogeveen Y, Bamps C, Burfield I, Van Swaay C. 2008. High Nature Value Farmland in Europe - An Estimate of the Distribution Patterns on the Basis of Land Cover and Biodiversity Data. Office for Official Publications of the European Communities, Luxembourg.

Pe'er G et al. 2017. Is the CAP Fit for purpose ? German Centre for Integrative Biodiversity Research (iDiv) Halle-Jena-Leipzig, Leipzig.

PECBMS. 2007. Species classification. Available from http://www.ebcc.info/art-301/ (accessed January 1, 2014).

PECBMS. 2018. Pan-European common Bird monitoring scheme. Available from https://pecbms.info (accessed July 16, 2018).

Pellissier V, Touroult J, Julliard R, Siblet JP, Jiguet F. 2013. Assessing the Natura 2000 network with a common breeding birds survey. Animal Conservation 16:566-574.

Rada S, Schweiger O, Harpke A, Kühn E, Kuras T, Settele J, Musche M. 2019. Protected areas do not mitigate biodiversity declines: A case study on butterflies. Diversity and Distributions 25:217-224.

Schmucki R et al. 2016. A regionally informed abundance index for supporting integrative analyses across butterfly monitoring schemes. Journal of Applied Ecology 53:501-510.

Thomas JA. 2016. Butterfly communities under threat. Science 353:216-218.

Van Der Sluis T et al. 2016. How much Biodiversity is in Natura 2000? The "Umbrella Eff ect" of the European Natura 2000 protected area network. Alterra Wageningen UR (University \&

This article is protected by copyright. All rights reserved. 
Reserch Centre), Wageningen.

Van Swaay C et al. 2007. The European Butterfly Indicator for Grassland species: 1990-2015. De Vlinderstichting, Wagennigen.

Van Swaay C, Warren M, Loïs G. 2006. Biotope Use and Trends of European Butterflies. Journal of Insect Conservation 10:189-209.

Verovnik R, Govedič M, Šalamun A. 2011. Is the Natura 2000 network sufficient for conservation of butterfly diversity? A case study in Slovenia. Journal of Insect Conservation 15:345-350.

Virkkala R, Rajasärkkä A. 2007. Uneven regional distribution of protected areas in Finland: Consequences for boreal forest bird populations. Biological Conservation 134:361-371.

Wood S. 2011. Fast stable restricted maximum likelihood and marginal likelihood estimation of semiparametric generalized linear models. Journal of the Royal Statistical Society: Series B 73:3-36.

Zhang Y. 2013. Likelihood-based and Bayesian methods for Tweedie compound Poisson linear mixed models. Statistics and Computing 23:743-757.

This article is protected by copyright. All rights reserved. 


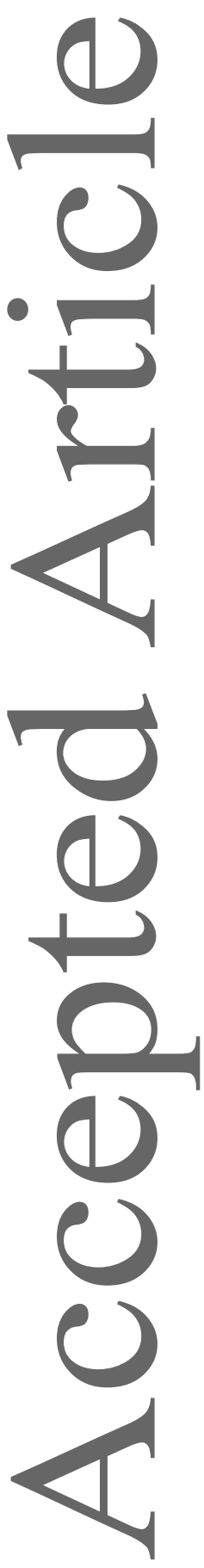

This article is protected by copyright. All rights reserved. 


\section{FIGURE CAPTIONS}

Figure 1 Centroids of monitoring sites used in this study, from (a) national Breeding Bird surveys (BBS) and (b) Butterfly Monitoring Schemes (BMS).

Figure 2. Number of bird (upper panels) and butterfly (lower panels) species showing a positive (Pos.) or negative (Neg.) relationship between abundance and the Natura 2000 coverage in a $1000 \mathrm{~m}$ radius around the monitoring sites. The relationship between N2000 and species abundance was tested without and with land-cover covariates to identify whether the designation effect was due to broad landscape characteristics. Colour represents affiliation of the species to woodlands, farmland, grassland specialists, or non-specialists. Transparent colours indicate non-significant $(\mathrm{P}>0.05)$ relationships.

Figure 3. Relationship between the species specialization index (SSI) of bird and butterfly species and the slope of the relationship between their abundance and the coverage of Natura 2000 in a $1000 \mathrm{~m}$ radius around monitoring sites (eq.2).

This article is protected by copyright. All rights reserved. 
(a)

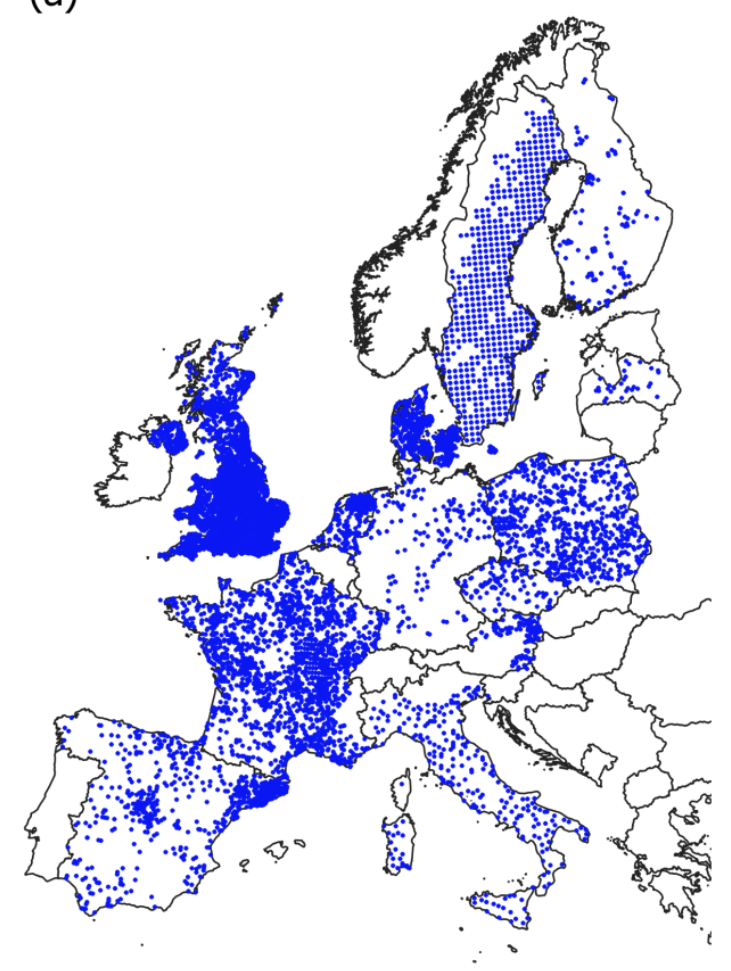

(b)

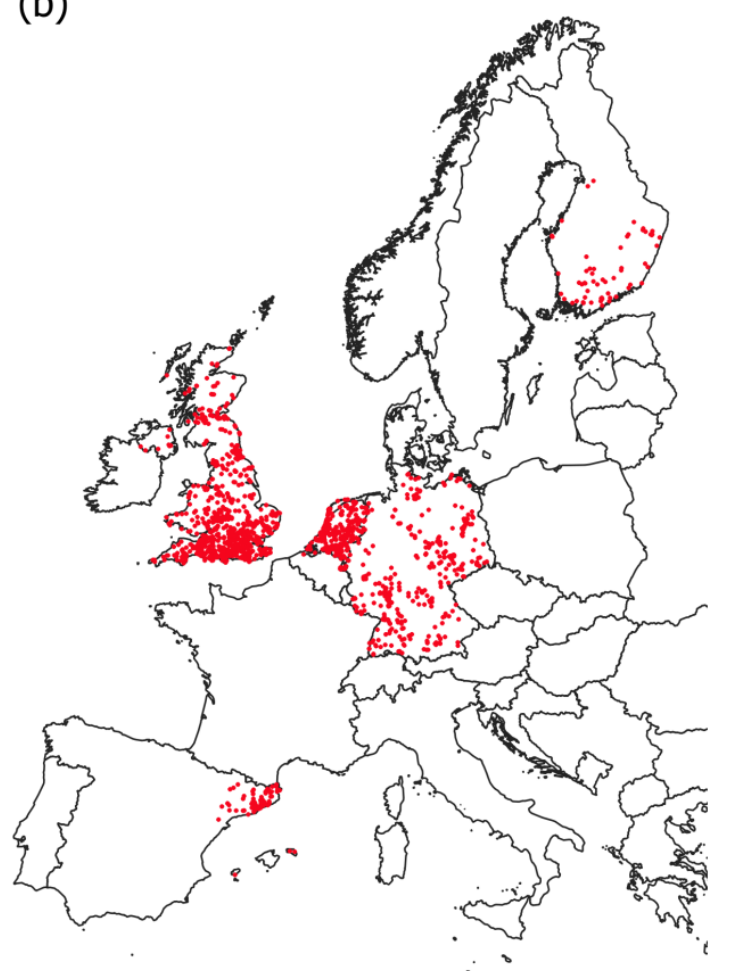

Figure 1. Centroids of monitoring sites used in this study, from (a) national Breeding Bird surveys (BBS) and (b) Butterfly Monitoring Schemes (BMS).

This article is protected by copyright. All rights reserved. 


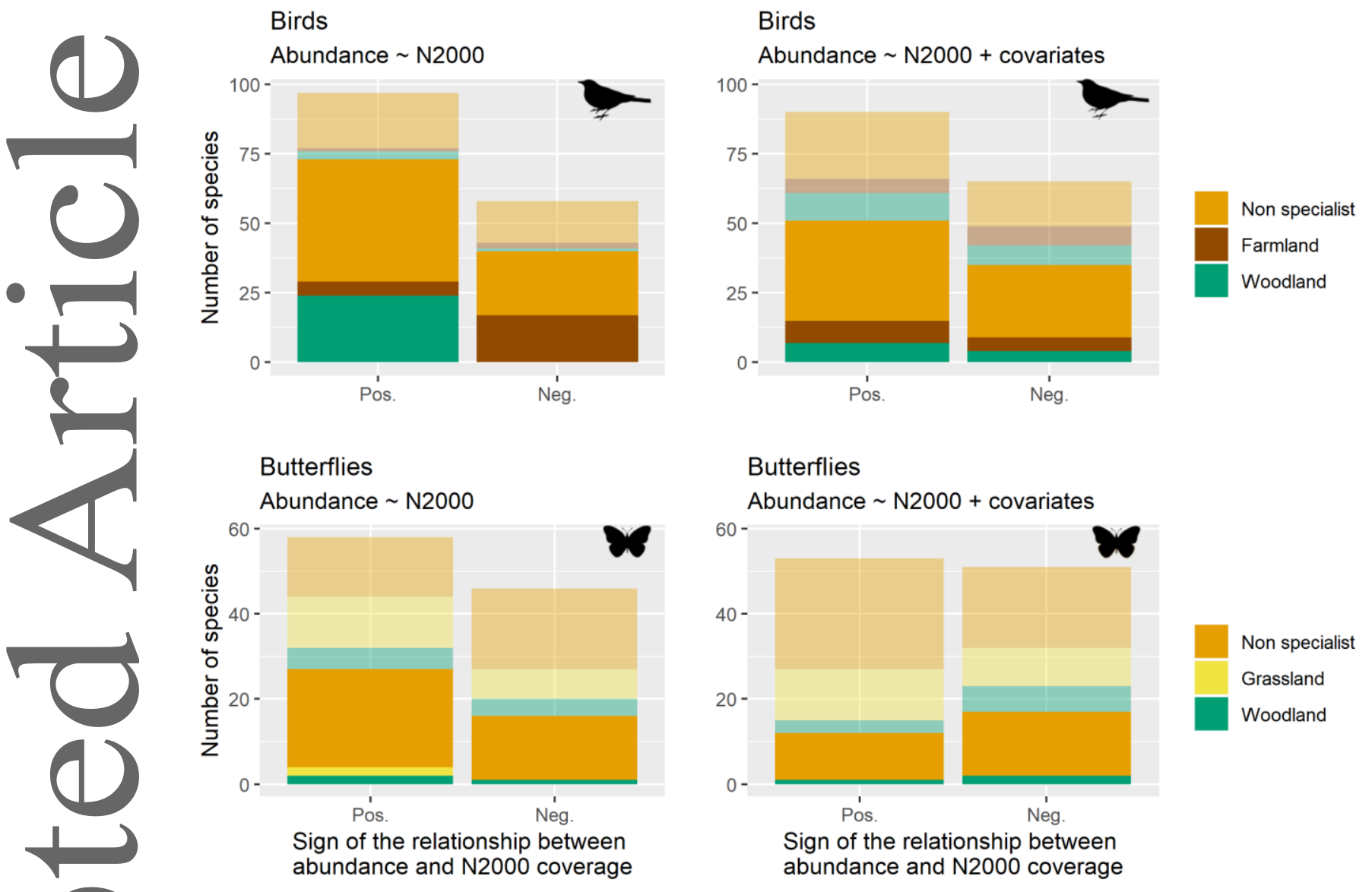

Figure 2. Number of bird (upper panels) and butterfly (lower panels) species showing a positive (Pos.) or negative (Neg.) relationship between abundance and the Natura 2000 coverage in a $1000 \mathrm{~m}$ radius around the monitoring sites. The relationship between $\mathrm{N} 2000$ and species abundance was tested without and with land-cover covariates to identify whether the designation effect was due to broad landscape characteristics. Colour represents affiliation of the species to woodlands, farmland, grassland specialists, or non-specialists. Transparent colours indicate non-significant $(\mathrm{P}>0.05)$ relationships.

This article is protected by copyright. All rights reserved. 

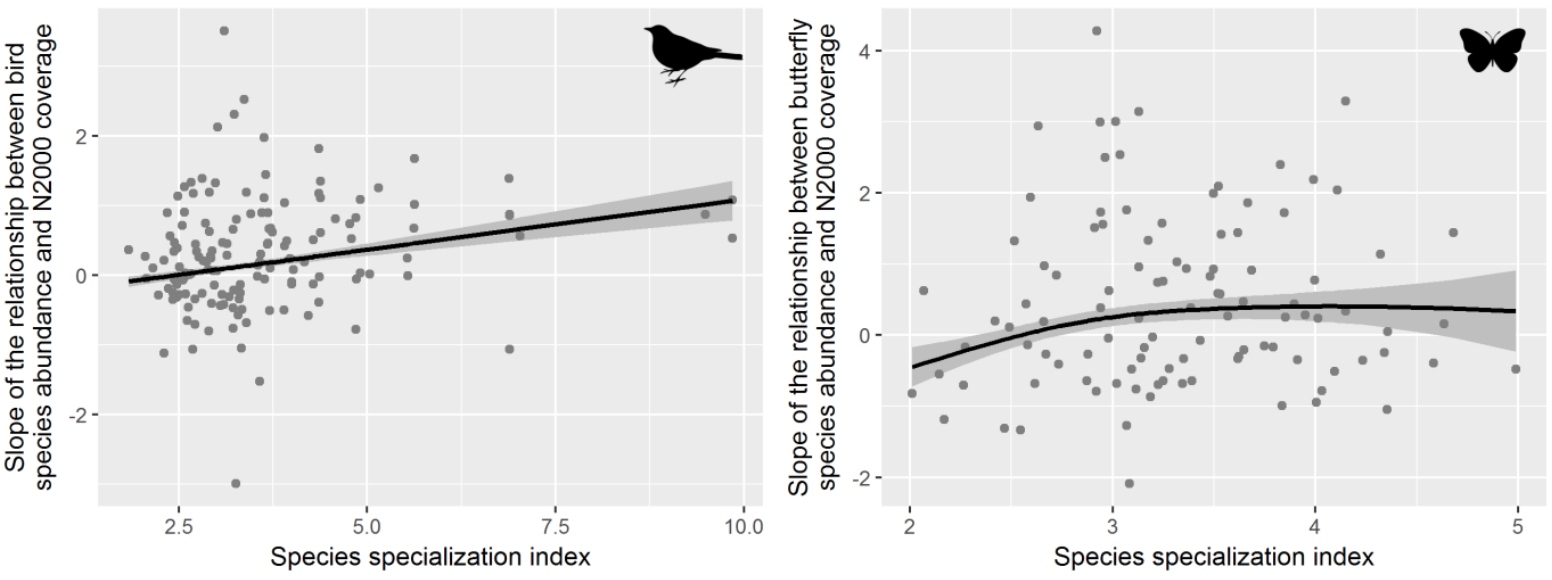

Figure 3. Relationship between the species specialization index (SSI) of bird and butterfly species and the slope of the relationship between their abundance and the coverage of Natura 2000 in a $1000 \mathrm{~m}$ radius around monitoring sites (eq.2).

This article is protected by copyright. All rights reserved. 